\title{
Cellulose Whisker/Epoxy Resin Nanocomposites
}

\author{
Liming Tang ${ }^{\dagger}$ and Christoph Weder*, ${ }^{*}$,
}

Department of Macromolecular Science and Engineering, Case Western Reserve University, 2100 Adelbert Road, Cleveland, Ohio 44106, and Adolphe Merkle Institute and Fribourg Center for Nanomaterials, University of Fribourg, CH-1700 Fribourg, Switzerland

\begin{abstract}
New nanocomposites composed of cellulose nanofibers or "whiskers" and an epoxy resin were prepared. Cellulose whiskers with aspect ratios of $\sim 10$ and $\sim 84$ were isolated from cotton and sea animals called tunicates, respectively. Suspensions of these whiskers in dimethylformamide were combined with an oligomeric difunctional diglycidyl ether of bisphenol A with an epoxide equivalent weight of 185-192 and a diethyl toluenediamine-based curing agent. Thin films were produced by casting these mixtures and subsequent curing. The whisker content was systematically varied between 4 and $24 \% \mathrm{v} / \mathrm{v}$. Electron microscopy studies suggest that the whiskers are evenly dispersed within the epoxy matrix. Dynamic mechanical thermoanalysis revealed that the glass transition temperature $\left(T_{\mathrm{g}}\right)$ of the materials was not significantly influenced by the incorporation of the cellulose filler. Between room temperature and $150{ }^{\circ} \mathrm{C}$, i.e., below $T_{\mathrm{g}}$, the tensile storage moduli $\left(E^{\prime}\right)$ of the nanocomposites increased modestly, for example from $1.6 \mathrm{GPa}$ for the neat polymer to 4.9 and $3.6 \mathrm{GPa}$ for nanocomposites comprising $16 \% \mathrm{v} / \mathrm{v}$ tunicate or cotton whiskers. The relative reinforcement was more significant at $185^{\circ} \mathrm{C}$ (i.e., above $T_{\mathrm{g}}$ ), where $E^{\prime}$ was increased from $\sim 16 \mathrm{MPa}$ (neat polymer) to $\sim 1.6 \mathrm{GPa}$ (tunicate) or $\sim 215$ MPa (cotton). The mechanical properties of the new materials are well-described by the percolation model and are the result of the formation of a percolating whisker network in which stress transfer is facilitated by strong interactions between the whiskers.
\end{abstract}

KEYWORDS: epoxy resin $\bullet$ cellulose $\bullet$ whisker $\bullet$ nanocomposite $\bullet$ percolating network $\bullet$ mechanical reinforcement

\section{INTRODUCTION}

Significant attention has been devoted in the past two decades toward the development and investigation of polymer nanocomposites, in which the incorporation of a mechanically robust, high-aspect-ratio nanoscale filler significantly enhances the mechanical properties compared to the neat polymer or conventional composites (1). Nanofillers such as clay, silica, and carbon nanotubes, in which at least one of the dimensions is on the length scale of a few nanometers, have been extensively exploited (2). Cellulose nanofibers are currently attracting particular interest in both academia and industry, because of the abundance and renewable nature of cellulose, and the outstanding mechanical properties of cellulose nanocrystals (3-8). The highly crystalline rodlike particles, commonly referred to as nanowhiskers or simply whiskers, can be isolated from a variety of renewable sources including wood, cotton, straw, bacteria, and sea animals called tunicates (9). They generally display high elastic moduli 100-150 GPa $(10,11)$ (depending on the source), and aspect ratio (10-100), with diameters that range from 4 to $20 \mathrm{~nm}$ (3). Some 15 years ago, Favier et al. reported a significant improvement of the mechanical properties (in particular increased stiffness) upon incorporation of a small amount of cellulose whiskers isolated from tunicates into a poly(styrene-co-butyl acrylate)

*Corresponding author. E-mail: christoph.weder@unifr.ch.

\footnotetext{
† Case Western Reserve University.
}

* University of Fribourg. latex (12). The formidable mechanical enhancement observed in these materials was explained by the formation of a percolating whisker network in the polymer matrix, in which stress transfer among the whiskers is facilitated by hydrogen-bonding. Since then, an extensive list of nanocomposites comprising cellulose whiskers has been explored, involving different kinds of cellulose whiskers as well as a broad range of polymeric matrixes, including poly(ethylene oxide) $(13,14)$, poly(vinyl chloride) (15), $\operatorname{poly}(\beta$ hydroxyoctanoate) (16), starch (17), polypropylene (18), poly(caprolactone) (19), ethylene oxide/epichlorohydrin copolymers (20-24), polystyrene (21), polybutadiene (21), poly(vinyl alcohol) (25), poly(butyl methacrylate) (26), and polyurethanes $(27,28)$.

Epoxy resins represent a class of polymeric materials whose applications are extensive and range from coatings, to adhesives to composite materials for electronics, sporting goods and others (29). The incorporation of nanofillers into epoxy resins can lead to a combination of high stiffness and strength, and good fatigue resistance (30), which is, for example, desirable for applications in the aerospace sector (31). Although epoxy resins represent one of the most important classes of thermosetting polymers, there have been only few reports on the use of cellulose nanocrystals as reinforcing fillers in such resins. Eichhorn et al. $(10,11)$ investigated the stiffness of cellulose whisker/epoxy system using Raman spectroscopy and highlighted the importance of the interface between matrix and nanofiller. Drzal et al. (32) recently reported that the modulus increased approximately 6 fold upon incorporation of $5 \% \mathrm{w} / \mathrm{w}$ microfibrillated cellulose (but not cellulose whiskers) into an epoxy matrix. 


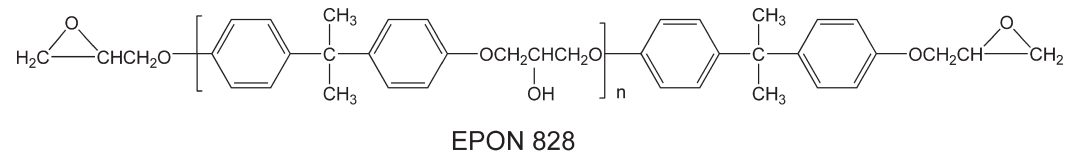

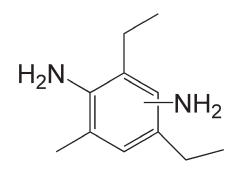

Epikure W

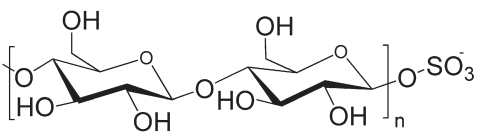

Nanowhisker

FIGURE 1. Chemical structures of the oligomeric difunctional diglycidyl ether of bisphenol A (Epon 828) and the diethyl toluenediaminebased cross-linker (Epikure W) used as monomers for the epoxy resins investigated, and of the cellulose whiskers isolated through sulfuric acid hydrolysis of tunicate or cotton cellulose pulp.

Cavaillé et al. $(33,34)$ studied waterborne epoxy coatings into which low concentrations of tunicate whiskers were incorporated; the resulting nanocomposites were characterized by an increased stiffness in the rubbery state, but the requirement to process from water limits the choices of compatible resins and curing agents and therewith the possible applications for this type of system.

Recent studies by our group $(23,35,36)$ and others $(37,38)$ have shown that stable cellulose whisker suspensions in polar aprotic solvents such as dimethyl formamide (DMF), dimethyl sulfoxide (DMSO) and $\mathrm{N}$-methyl pyrrolidine (NMP) can be produced by lyophilization of aqueous whisker dispersions and subsequent redispersion of the resulting whisker aerogel by ultrasonication. Nanocomposites are then accessible by mixing organic whisker dispersions with an organo-soluble polymer of choice. Here, we report the fabrication and investigation of nanocomposites based on a conventional epoxy resin and cellulose whiskers isolated from cotton and tunicates based on this approach. We also show that the processing framework can be improved by avoiding lyophilization (which is expensive) and redispersion of the dry material by prolonged ultrasonication (which can cause mechanical degradation of the whiskers (35)) but using a simple solvent exchange scheme instead.

\section{EXPERIMENTAL SECTION}

Materials. All reagents, except acetone, which was dried over potassium carbonate, were used as received. Acetone, dimethyl formamide (DMF), and sulfuric acid were purchased from Fisher Scientific. EPON 828 and EPIKURE W (Figure 1) were received from Miller-Stephenson Chemical Company, Inc. Cellulose whiskers from cotton were isolated using the general procedure of Dong et al. (39) with slight modifications as described in detail before (21); the concentration of the aqueous whisker dispersion produced was determined gravimetrically to be $\sim 20 \mathrm{mg} / \mathrm{mL}$. Cellulose whiskers from tunicates were isolated using the general procedure of Favier et al. with slight modifications (21); the concentration of the aqueous whisker dispersion produced was determined gravimetrically to be $\sim 8 \mathrm{mg} / \mathrm{mL}$. A literature value of $1.46 \mathrm{~g} / \mathrm{mL}$ was used for the density of microcrystalline cellulose (40). The density of the neat epoxy resin was measured in a density column and found to be $1.10 \mathrm{~g} / \mathrm{mL}$.

Instrumentation. Transmission electron micrographs (TEMs) were acquired using a JEOL 1200EX Transmission Electron Microscope. TEM samples were prepared on either Formvar/ carbon-coated copper grids (aqueous dispersions) or 400 mesh carbon-coated copper grids (DMF dispersions) using a standard uranyl acetate negative staining method (41). Scanning electron microscope images (SEMs) were acquired with a Hitachi S-4700 field-emission microscope. The samples were frozen in liquid nitrogen, then fractured, mounted and sputter-coated with palladium. A Fisher FS6OH ultrasonic bath was used for ultrasonication of whisker dispersions.

Dispersion of Lyophilized Cellulose Whiskers in DMF. Aqueous cellulose whisker suspensions ( $\sim 8 \mathrm{mg}$ of dry cellulose per $1 \mathrm{~mL}$ of $\mathrm{H}_{2} \mathrm{O}$ ) were frozen in an acetone/dry ice cooled stainless steel container and subsequently lyophilized. The freeze-dried whiskers were mixed with DMF at a concentration of $5 \mathrm{mg} / \mathrm{mL}$ and dispersed via ultrasonication for $4-6 \mathrm{~h}$ (tunicate whiskers) or $12-16 \mathrm{~h}$ (cotton whiskers). The temperature of the water bath was kept below $40{ }^{\circ} \mathrm{C}$. The suspensions were allowed to settle overnight before the top layer, in which the whiskers were well-dispersed, was collected by decanting, leaving behind any sediments at the bottom, which were especially noticeable in case of cotton whisker dispersions. The final concentrations of the whisker dispersions thus produced were determined gravimetrically to be 5 and $2.5 \mathrm{mg} / \mathrm{mL}$ for tunicate and cotton whiskers, respectively. The dimensions of the whiskers in these dispersions were elucidated by TEM.

Dispersion of Cellulose Whiskers in DMF by Solvent Exchange. Cellulose whisker organogels were prepared from aqueous dispersions using a solvent exchange sol-gel process similar to the one previously described (21). Acetone (150 mL) was gently added to a beaker containing aqueous whisker dispersions ( $50 \mathrm{~mL}, 5-8 \mathrm{mg} / \mathrm{mL}$ ), which had been produced by diluting the as-prepared aqueous dispersions with water. In all cases, this resulted in the formation of an organic layer on top of the aqueous dispersion. The organic layer was exchanged 1-2 times daily, until the bottom portion had assembled into a mechanically coherent whisker-acetone gel, typically within 3-7 days. The acetone layer was periodically (typically $1-2$ times a day) gently agitated to facilitate solvent exchange. When the solvent exchange was no longer visible (refraction at the sol/ gel interface ceased), the acetone gel was released from the beaker to a glass bottle, and the solvent was exchanged twice more against dry acetone over the course of one day. The cellulose whisker/acetone gels thus produced were subsequently transferred to a $100 \mathrm{~mL}$ glass bottle and DMF was added. The gels redispersed upon gentle shaking within several minutes. The dispersion was then transferred to a $100 \mathrm{~mL}$ flask and acetone (and perhaps a small amount of DMF) was evaporated on a rotavap. The concentrations of the whisker dispersions thus prepared were determined gravimetrically to be $4 \mathrm{mg} / \mathrm{mL}$ (tunicate whiskers) and $8 \mathrm{mg} / \mathrm{mL}$ (cotton whiskers). The dimensions of the whiskers in these dispersions were elucidated by TEM.

General Procedure for Fabrication of Cellulose/Epoxy Nanocomposites. EPON 828 (0.16 g) and EPIKURE W (0.04 g) were mixed with the appropriate amount of whisker dispersion in DMF $(4 \mathrm{mg} / \mathrm{mL})$. The mixture was stirred for $30 \mathrm{~min}$ and then ultrasonicated for $10 \mathrm{~min}$. Subsequently, the suspension was 

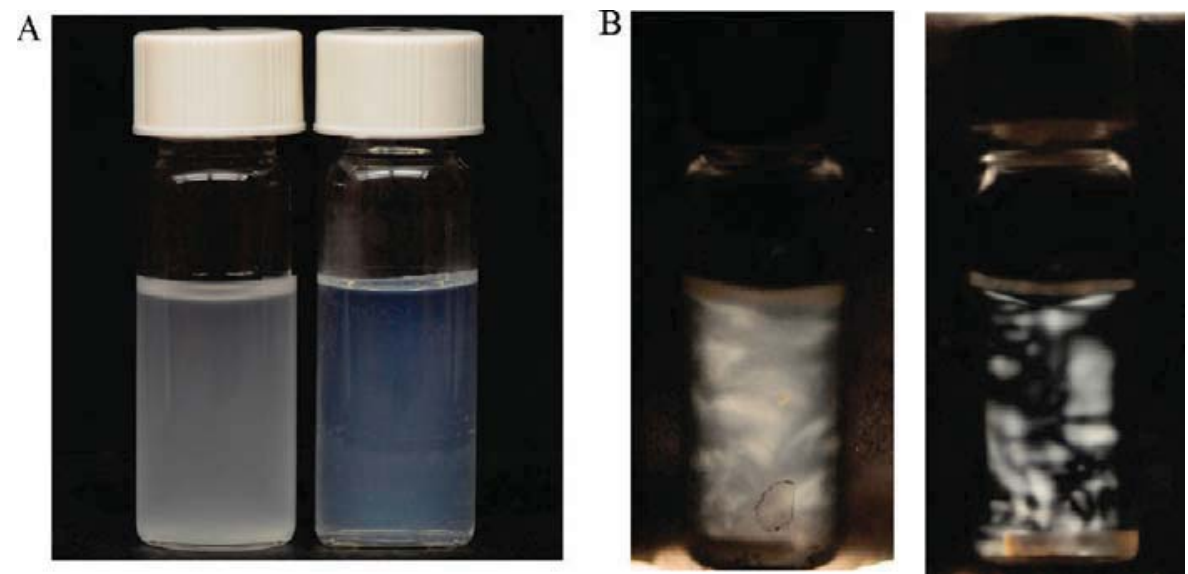

FIGURE 2. (A) Photographs of cotton whisker dispersions in DMF made by (left) lyophilization $(2.5 \mathrm{mg} / \mathrm{mL}$ ) and (right) redispersion of acetone/ whisker gels $(8 \mathrm{mg} / \mathrm{mL})$; (B) photographs of $2.5 \mathrm{mg} / \mathrm{mL}$ cotton whisker dispersions in DMF viewed through cross polarizers made by (left) lyophilization and (right) redispersion of acetone/whisker gels.

cast into a Teflon Petri dish and the solvent was evaporated at room temperature in a well-ventilated hood over the course of $24 \mathrm{~h}$. The Petri dish was subsequently placed into a vacuum oven and the sample was dried under a dynamic vacuum for 2 days at $60{ }^{\circ} \mathrm{C}$, before the temperature was increased to 120 ${ }^{\circ} \mathrm{C}$ for $16 \mathrm{~h}$ to cure the epoxy resin. The films thus produced had a final thickness of $60-80 \mu \mathrm{m}$.

Dynamic Mechanical Thermal Analyses (DMTA). DMTA measurements were performed using a TA Instruments DMA 2980 on rectangular films (ca. $10 \times 4 \times 0.08 \mathrm{~mm}$ ) in tensile mode with an oscillation frequency of $1 \mathrm{~Hz}$, a static force of 10 $\mathrm{mN}$, an oscillation amplitude of $15.0 \mu \mathrm{m}$, and an automatic tension setting of $125 \%$. Measurements were carried out at a heating rate of $3{ }^{\circ} \mathrm{C} / \mathrm{min}$ (range of $25-200{ }^{\circ} \mathrm{C}$ ).

Conductometric Titration of Cellulose Whiskers. Surface charge densities of both cotton and tunicate cellulose whiskers were quantified by conductometric titration. Between 6.6 and $8.8 \mathrm{~mL}$ of aqueous dispersions of either cellulose source (whisker content $\sim 8 \mathrm{mg} / \mathrm{mL}$ ) were placed into a $250 \mathrm{~mL}$ beaker with $\sim 200 \mathrm{~mL}$ of deionized water. The suspensions were placed on a magnetic stir plate and stirred to maintain homogeneity. When a stable reading was reached, the suspensions were titrated with $0.01 \mathrm{M} \mathrm{KOH}$ by micropipet. Ionic equilibrium was determined from measurements of $\mathrm{pH}$ and conductivity upon addition of $50 \mu \mathrm{L}$ aliquots of dilute base solution using an AccumetAR50 (FisherScientific; accuTupH pH probe\#13-620-183; accumet conductivity probe \#13-620-163).

\section{RESULTS AND DISCUSSION}

The nanocomposites investigated in this study were based on an epoxy resin formed by the reaction of an oligomeric difunctional diglycidyl ether of bisphenol A with an epoxide equivalent weight of 185-192 and a diethyl toluenediamine-based curing agent in the presence of cellulose whiskers isolated from cotton and tunicates (Figure 1). These two types of cellulose whiskers were employed in a comparative manner; tunicate whiskers exhibit a much higher aspect ratio and more pronounced reinforcing effect than cotton whiskers, but the latter are produced from a more accessible and technologically more viable source $(23,39)$. In both cases, the controlled hydrolysis of cellulose pulp with sulfuric acid affords whiskers which display good dispersibility in water $(35,39)$. This is due to the presence of the negatively charged sulfate ester groups, which are a byproduct of the hydrolysis and cause electrostatic repulsion between the individual cellulose whiskers. Suspensions of such whiskers in organic solvents can be produced via lyophilization and subsequent redispersion, but the fraction of whisker that redisperses well can be quite low, especially in the case of cotton whiskers (38). We now discovered that the processing can be simplified and improved by avoiding lyophilization and redispersion but using a simple solvent exchange scheme instead. The method builds on our previous work on the fabrication of cellulose nanofiber templates through a sol/gel process (23), which involves the addition of a water-miscible nonsolvent for the whiskers to a homogeneous aqueous whisker dispersion to cause gelation by way of solvent exchange. Starting from aqueous dispersions comprising cellulose whiskers at a concentration $\sim 5-8 \mathrm{mg} /$ $\mathrm{mL}$, we prepared gels of both whisker types by solvent exchange with acetone (see Experimental Section for details). Rather than imbibing the gels with polymer solutions, as was done in our previous work, the gels were placed into DMF, in which they disintegrated within minutes-without ultrasonication-and formed homogeneous whisker dispersions, from which the acetone could readily be eliminated by evaporation. Visual comparison (light scattering, sedimentation) of dispersions prepared by this approach and by redispersion of lyophilized whiskers and the superior quality of stable birefringence (Figure 2 and Figure S1 in the Supporting Information) indicates qualitatively that the new route affords cellulose whisker dispersions of better quality, especially in the case of cotton whiskers. No sediments were observed upon dispersing cotton (and also tunicate, vide infra) whiskers by this method, suggesting that the dispersion is quantitative. By contrast, the yield for the redispersion of lyophilized cotton whiskers was about $50 \%$. This finding is supported by transmission electron microscopy (TEM) images of whiskers that were deposited from the original aqueous dispersions and the organic dispersions prepared by the two methods (Figure 3 and Figure S2 in the Supporting Information). Figure 3 a shows that cotton whiskers deposited from water are well isolated and exhibit an average width of $\sim 22 \pm 1 \mathrm{~nm}$ and a length of $\sim 200 \pm 20$ $\mathrm{nm}$ (42). The data agree well with our previous studies (21) 
A

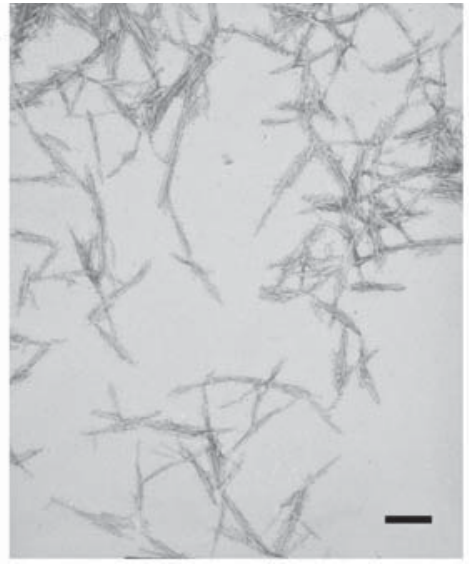

B

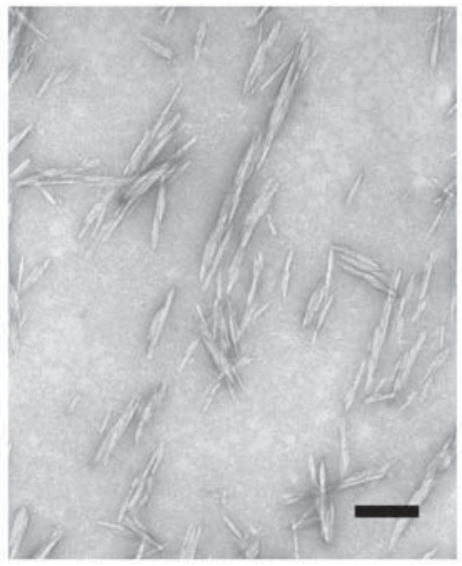

C

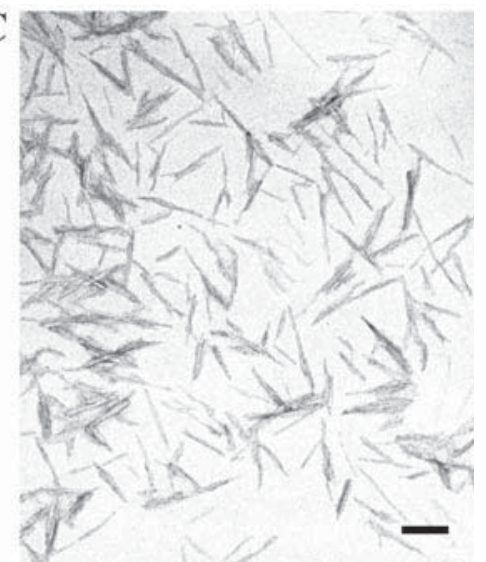

FIGURE 3. Transmission electron micrographs of (A) as-prepared cotton whiskers deposited from an aqueous dispersion; (B) cotton whiskers that were freeze-dried, redispersed in DMF by ultrasonication, and deposited from DMF; and (C) cotton whiskers that were deposited from $\mathrm{DMF}$ after water/acetone solvent exchange and redispersion of the acetone/whisker gel in $\mathrm{DMF}$; $\mathrm{scale}$ bars for $\mathrm{A}-\mathrm{C}=200 \mathrm{~nm}$.

and other work (39) and support the good reproducibility of the isolation process and the usefulness of using TEM images for particle sizing. The TEM image (Figure 3b) of lyophilized, redispersed cotton whiskers shows the formation of small bundles of whiskers and a decrease of their average length to $\sim 125 \pm 25 \mathrm{~nm}$ (42), whereas the diameter has not changed. This latter finding is attributed to the degradation during the prolonged ultrasonication time, which is consistent with a previous report (23). Figure 3 c shows the image of cotton whiskers redispersed in DMF by solvent exchange; they exhibit an average length of $185 \pm 21 \mathrm{~nm}$ and the width of $20 \pm 2 \mathrm{~nm}$ (42). Thus, redispersion of cotton whiskers in DMF (and presumably other organic solvents) is readily achieved in high quantity and with minimum impact on the whiskers by the solvent exchange scheme used here. The situation for tunicate whiskers is similar, although here the relative reduction in length upon freeze-drying and redispersion was less pronounced. Figure S2a and S2C in the Supporting Information show that tunicate whiskers that were either deposited directly from water or redispersed by solvent exchange have the same average width of $\sim 20 \pm 2$ $\mathrm{nm}$ and length of $\sim 1.7 \pm 0.2 \mu \mathrm{m}$. The TEM image (see Figure $\mathrm{S} 2 \mathrm{~b}$ in the Supporting Information) of lyophilized, redispersed tunicate whiskers reveals an average length of $\sim 1.2$ $\pm 0.17 \mu \mathrm{m}$; as for the cotton whiskers, this decrease is related to prolonged ultrasonication and highlights the importance of rapid and effective redispersion, which can, as our data show, be achieved through solvent exchange. The dispersion of tunicate whiskers in DMF was quantitative for both processing schemes. Together, the data suggest that the dispersibility of the tunicate whiskers in DMF is slightly better than that of cotton. Conductometric titration revealed that the concentration of negatively charged sulfate groups on the tunicate whiskers is $\sim 80 \mathrm{mmol} \mathrm{SO}_{4}{ }^{-} / \mathrm{kg}$ cellulose; this is higher than that on the cotton whiskers $\left(\sim 55 \mathrm{mmol} \mathrm{SO}_{4}{ }^{-}\right.$/ $\mathrm{kg}$ cellulose). The electrostatic repulsion among the sulfate groups between tunicate whiskers is one key factor for its good dispersibility in DMF and for the difference in the morphology of polymer nanocomposites produced from such dispersions, and hence, the better dispersibility of the tunicate whiskers is not a surprise.
In a comparative study, nanocomposites composed of either type of whiskers (tunicate and cotton) and the epoxy resin were prepared by combining suspensions of the whiskers in DMF (dispersion made by both methods were compared) with the monomers, solution casting, drying, and subsequent curing at $120{ }^{\circ} \mathrm{C}$ for $16 \mathrm{~h}$. The whisker content was systematically varied between 4 and $24 \% \mathrm{v} / \mathrm{v}$ (between 5 and $30 \% \mathrm{w} / \mathrm{w}$ ), i.e. most samples contain the cellulose in a concentration above the percolation threshold determined for tunicate and cotton whiskers in a polar matrix as previously determined ( 1 and $6.6 \% \mathrm{v} / \mathrm{v}$, respectively) (3). All films thus produced were transparent, suggesting good dispersion of the whiskers in the epoxy matrix (see Figure S3 in the Supporting Information). The morphologies of the nanocomposites were further characterized by scanning electron microscopy (SEM) images. Figure 4 shows the fractured surfaces of a film of the neat epoxy resin and of nanocomposite films with $\sim 8 \% \mathrm{v} / \mathrm{v}$ cotton and $\sim 8 \% \mathrm{v} / \mathrm{v}$ tunicate whiskers made by the solvent exchange route. The micrographs clearly show the cellulose whiskers in the epoxy matrix. Their width of $\sim 22 \mathrm{~nm}$ corresponds well to the one determined by TEM. They appear to be generally wellindividualized and distributed in the matrix, but some aggregates composed of a few whiskers can also be observed. The images of the corresponding nanocomposites produced from dispersions that were made from lyophilized whiskers (see Figures S3 and S4 in the Supporting Information) also reflect good dispersion of the whiskers in the epoxy matrix, although mechanical data (vide infra) suggest some aggregation for the cotton-based materials.

The mechanical behavior of the new nanocomposites was analyzed using dynamic mechanical thermal analysis (DMTA). Figure 5 a shows the tensile storage modulus $E^{\prime}$ of tunicate whisker composites made by the solvent exchange route as a function of temperature and whiskers content. The tunicate whisker nanocomposites made from the lyophilized whiskers show a virtually identical behavior (see Figure S5 in the Supporting Information). The neat epoxy resin displays the typical behavior of an amorphous thermoset. At temperatures below the $T_{\mathrm{g}}$, the tensile storage modulus of the polymer showed little temperature dependence and only 

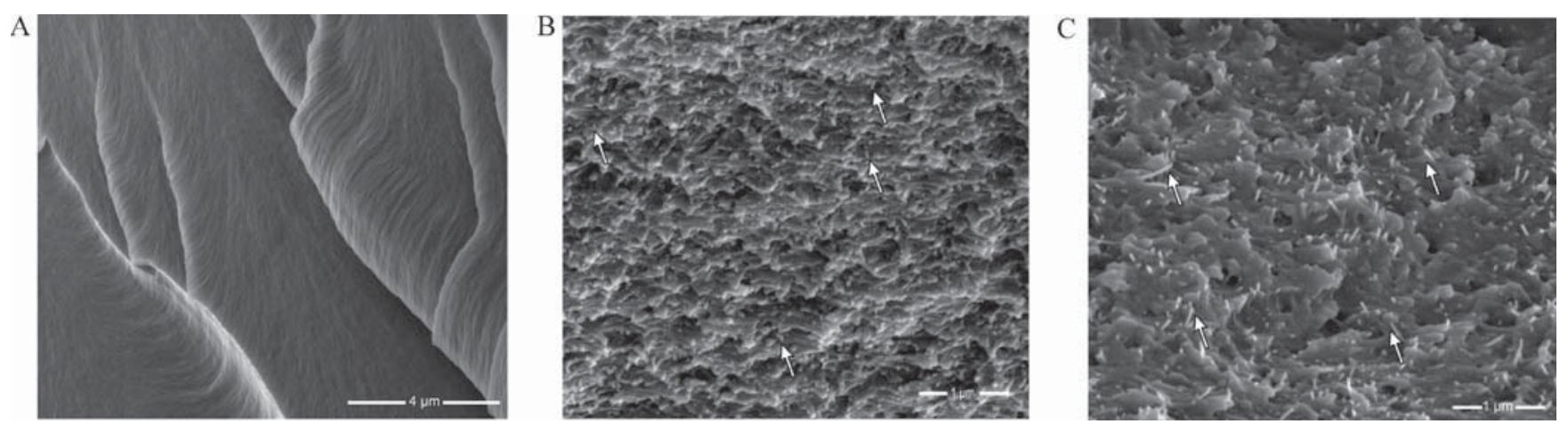

FIGURE 4. SEM images of the fractured surfaces of (A) the neat epoxy resin; (B) a cellulose whisker/epoxy nanocomposite comprising $\sim 8 \%$ $\mathrm{v} / \mathrm{v}$ cotton whiskers made by redispersion of acetone/whisker gels in DMF; (C) a cellulose whisker/epoxy nanocomposite comprising $\sim 8 \% \mathrm{v} / \mathrm{v}$ tunicate whiskers made by redispersion of acetone/whisker gels in DMF.
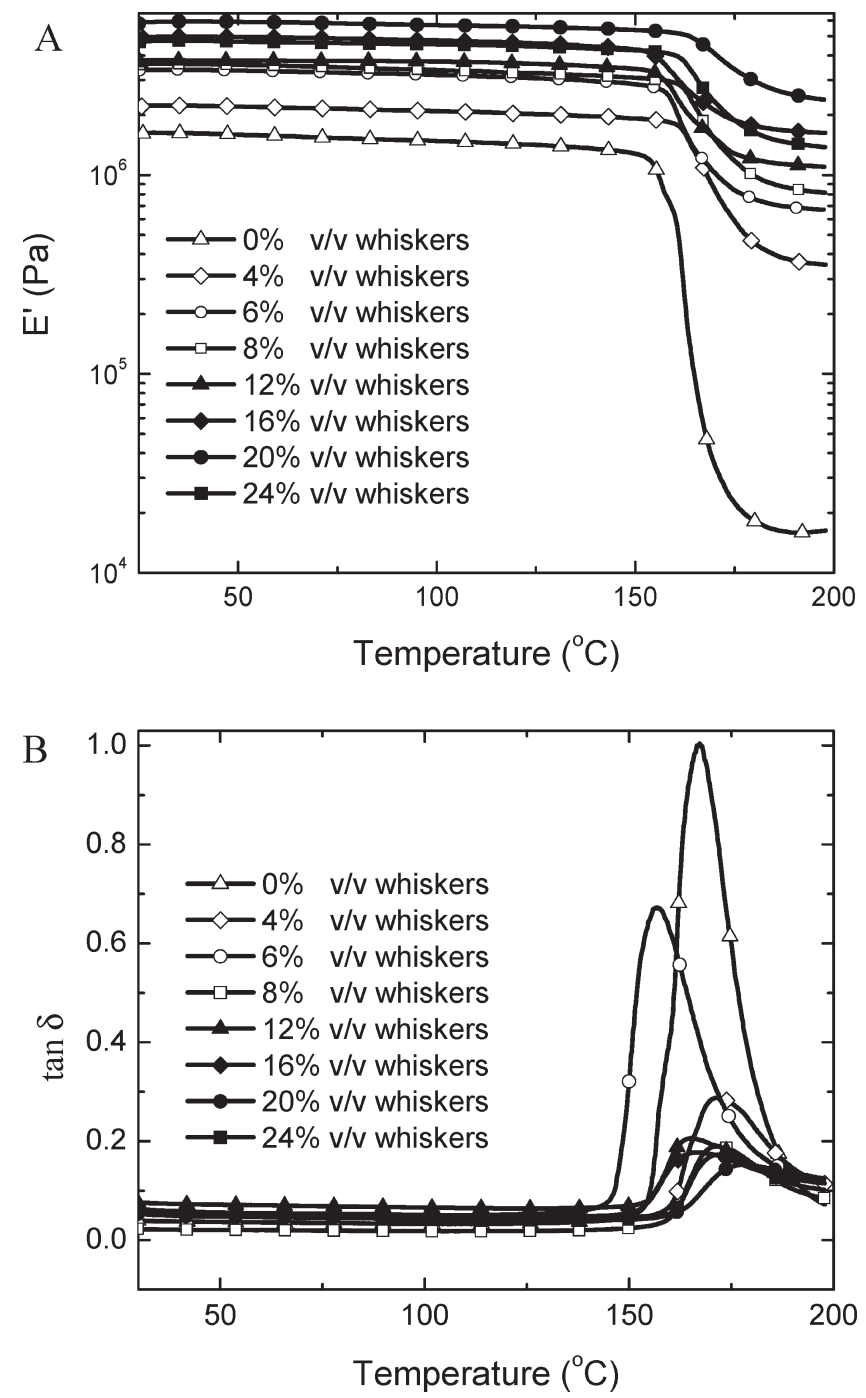

FIGURE 5. DMTA data of tunicate whisker/epoxy nanocomposites made by redispersion of acetone/whisker gels in DMF. (A) Tensile storage moduli $E^{\prime}$ and (B) Loss factor $(\tan \delta)$ of the films as a function of temperature. The nanocomposites contain between 0 and $24 \%$ $\mathrm{v} / \mathrm{v}$ tunicate whiskers.

slightly decreased with increasing temperature; as a point of reference, $E^{\prime}$ at $30^{\circ} \mathrm{C}$ was $1.6 \mathrm{GPa}$. Above ca. $160^{\circ} \mathrm{C}$ (i.e., the onset of the glass transition) $E^{\prime}$ drops by more than 2 orders of magnitude, to reach (at ca. $185^{\circ} \mathrm{C}$ ) a rubbery plateau at a level of $\sim 15 \mathrm{MPa}$. Qualitatively, the DMTA traces of the tunicate whisker nanocomposites (Figure 5a) display a similar behavior, but the storage moduli are significantly higher than that of the neat matrix. Even below $T_{\mathrm{g}} E^{\prime}$ increased significantly. For example, at $30{ }^{\circ} \mathrm{C} E^{\prime}$ increased from 1.6 GPa for the neat epoxy to 2.2 and 5.7 GPa for nanocomposites comprising 4 and $20 \%$ v/v tunicate whiskers, respectively. A more dramatic mechanical reinforcement was observed above $T_{\mathrm{g}}$. For example, at $185^{\circ} \mathrm{C}$, $E^{\prime}$ of the nanocomposite containing $4 \% \mathrm{v} / \mathrm{v}$ tunicate whiskers exhibits a modulus of $355 \mathrm{MPa}$, which represents a 22fold enhancement over that of the neat matrix (15 MPa). The reinforcement increased with the volume fraction of whiskers. At a content of $20 \% \mathrm{v} / \mathrm{v}$ whiskers, $E^{\prime}$ was $2.4 \mathrm{GPa}, 150$ times greater than that of the neat epoxy. The fact that the samples comprising $24 \%$ v/v whiskers show a slightly lower modulus may be explained with aggregation of whiskers at higher concentrations. Figure $5 b$ displays the evolution of the mechanical loss factor $\tan \delta$ of the tunicate whisker/ epoxy nanocomposites as a function of temperature and whisker content. The neat epoxy resin shows a peak at 165 ${ }^{\circ} \mathrm{C}$, which correlates with the glass-rubber transition of the polymer matrix. The incorporation of whiskers slightly shifts the tan $\delta$ peak to higher temperature, although this trend is not apparent for all samples, and its magnitude is slightly lowered. This can be related $(4,33)$ to interactions between the matrix and the surface of the cellulose. Given the surface chemistry of the whiskers, we speculate that hydrogen bond interactions between the hydroxyl groups on the surface of the whiskers with polar sites of the epoxy chains, such as hydroxyethers and unreacted amines, are at play (43).

Nanocomposites containing between 6 and $24 \% \mathrm{v} / \mathrm{v}$ cotton whiskers were also studied. Figure $6 \mathrm{a}$ shows the tensile storage moduli $E^{\prime}$ of cotton whisker nanocomposites made by the solvent exchange route as a function of temperature and whisker content. The thermomechanical properties of these materials display similar trends as those of the tunicate whisker nanocomposites, but the storage moduli are lower. For example at $30^{\circ} \mathrm{C}$ (below the $T_{\mathrm{g}}$ ), $E^{\prime}$ increased from $1.6 \mathrm{GPa}$ for the neat epoxy to 2.7 and $3.1 \mathrm{GPa}$ for nanocomposites containing 6 and $20 \% \mathrm{v} / \mathrm{v}$ cotton whiskers, respectively. Similarly, a significant reinforcement of mechanical properties was observed above $T_{\mathrm{g}}$. At $185{ }^{\circ} \mathrm{C}$, nanocomposites with 6 and $20 \% \mathrm{v} / \mathrm{v}$ cotton whiskers exhibit 

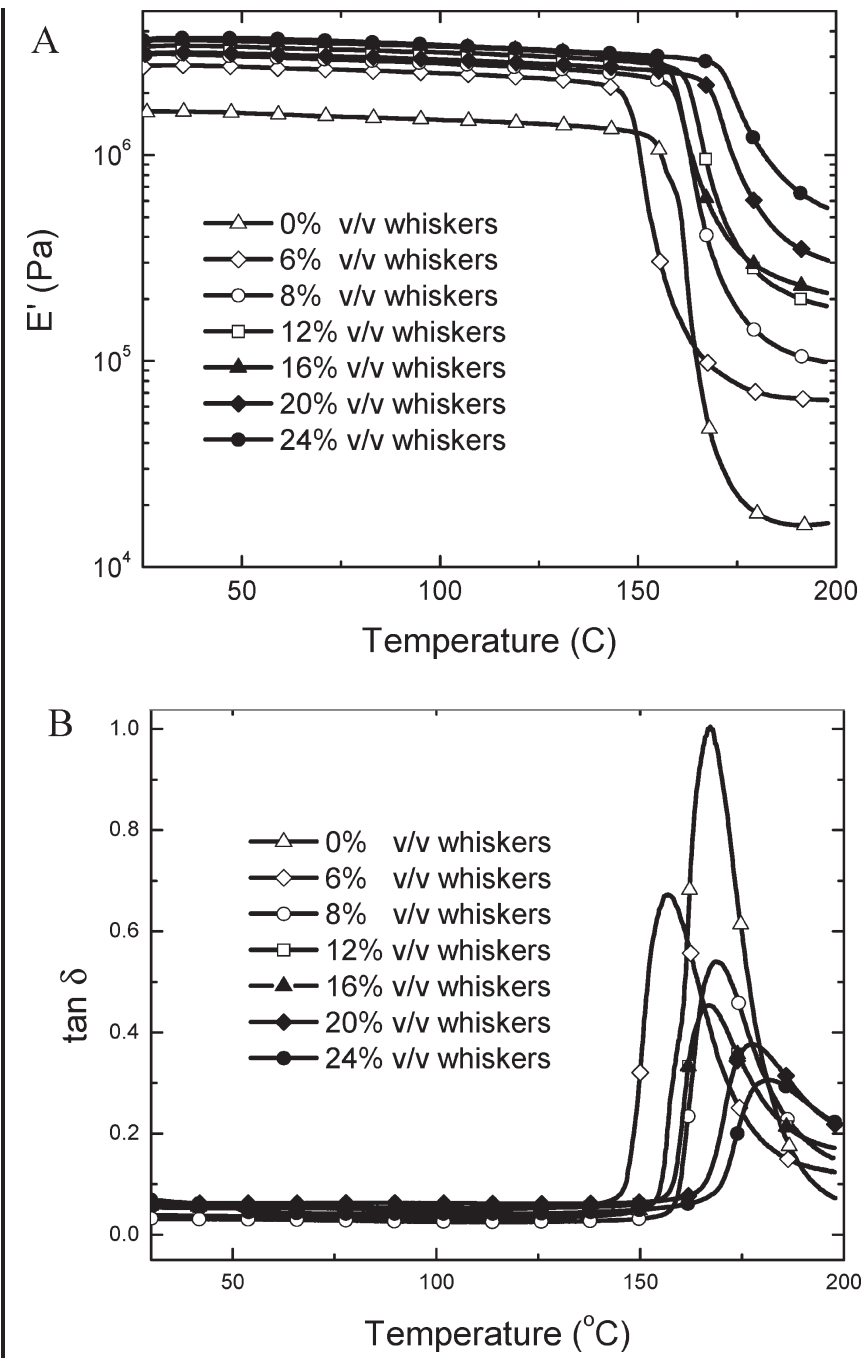

FIGURE 6. DMTA data of cotton whisker/epoxy nanocomposites made by redispersion of acetone/whisker gels in DMF. (A) Tensile storage moduli $E^{\prime}$ and (B) Loss factor ( $\tan \delta$ ) of the films as a function of temperature. The nanocomposites contain between 0 and $24 \%$ $\mathrm{v} / \mathrm{v}$ cotton whiskers.

moduli of 64 and $312 \mathrm{MPa}$, which are 4 and almost 20 times higher than that of the neat epoxy $(16 \mathrm{MPa})$. The fact that the nanocomposites comprising cotton whiskers display a less pronounced reinforcement effect than those based on tunicate whiskers is consistent with the lower aspect ratio and the lower modulus of cotton whiskers and previous findings by us (21) and others (11) who have compared the mechanical properties of cellulose whiskers and composites based on different whisker types and different surface properties of whiskers. Figure $5 b$ shows the changes of tan $\delta$ of nanocomposites with cotton whiskers as a function of temperature and whisker content and reveals a similar behavior as the tunicate-whisker nanocomposites discussed above.

The significant mechanical reinforcement observed for the present cellulose whisker/epoxy nanocomposites above $T_{\mathrm{g}}$ suggests the formation of rigid whisker networks where stress transfer is facilitated by hydrogen-bonding between the whiskers. This mechanism was demonstrated to be responsible for the reinforcement of several thermoplastic polymers $(3,22,23)$ and water-borne epoxy resins $(33,34)$

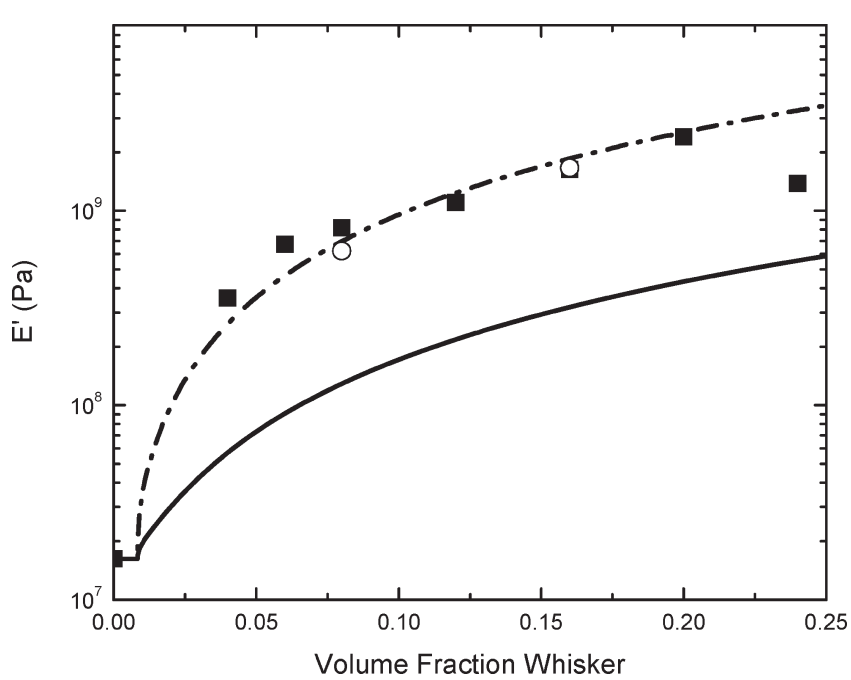

FIGURE 7. Tensile storage moduli $\left(E^{\prime}\right)$ of tunicate whisker/epoxy nanocomposites at $185{ }^{\circ} \mathrm{C}$ as a function of volume fraction of whiskers. Nanocomposites were fabricated by redispersion of acetone/ whisker gels in DMF (solid squares) or redispersion of lyophilized whiskers in DMF (open circles). The solid and dash-dotted lines represent values predicted by the percolation model $\left(E_{\mathrm{r}}^{\prime}=13.0\right.$ or $24.0 \mathrm{GPa}$, respectively).

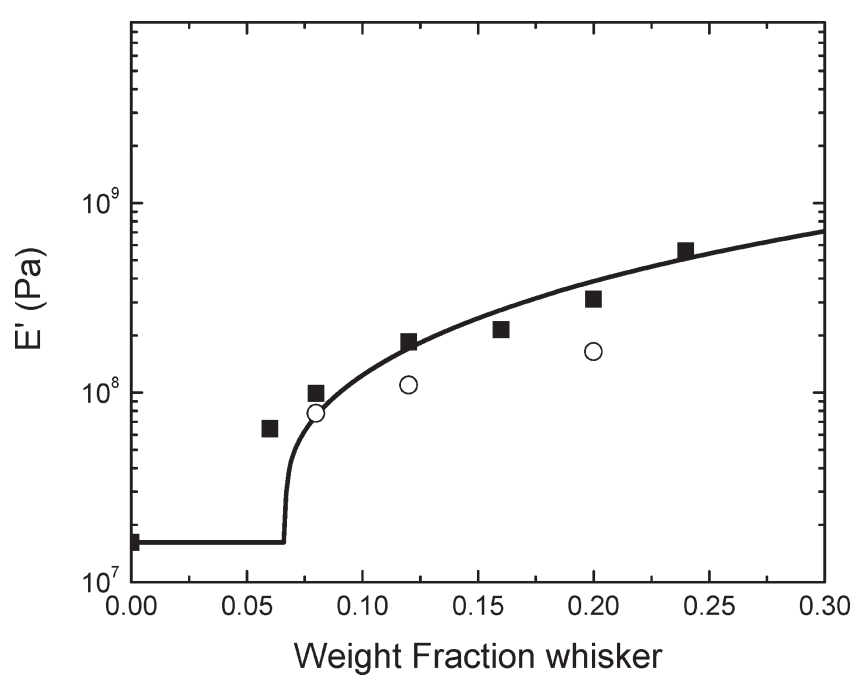

FIGURE 8. Tensile storage moduli $\left(E^{\prime}\right)$ of cotton whisker/epoxy nanocomposites at $185{ }^{\circ} \mathrm{C}$ as a function of volume fraction of whiskers. Nanocomposites were fabricated by redispersion of acetone/ whisker gels in DMF (solid squares) or redispersion of lyophilized whiskers in DMF (open circles). The solid line represents values predicted by the percolation model $\left(E_{\mathrm{r}}^{\prime}=4.0 \mathrm{GPa}\right)$.

by tunicate whiskers. It was shown that in the case of welldispersed systems, the mechanical properties can be predicted by a percolation model. Within the framework of the model, the tensile storage modulus of the nanocomposite $E^{\prime}$ can be expressed as $(44,45)$

$$
\begin{gathered}
E^{\prime}=\frac{\left(1-2 \psi+\psi X_{\mathrm{r}}\right) E_{\mathrm{s}}^{\prime} E_{\mathrm{r}}^{\prime}+\left(1-X_{\mathrm{r}}\right) \psi E_{\mathrm{r}}^{\prime 2}}{\left(1-X_{\mathrm{r}}\right) E_{\mathrm{r}}^{\prime}+\left(X_{\mathrm{r}}-\psi\right) E_{\mathrm{s}}^{\prime}} \\
\text { whisker/epoxy nanocomposites }
\end{gathered}
$$

with

$$
\psi=X_{\mathrm{r}}\left(\frac{X_{\mathrm{r}}-X_{\mathrm{c}}}{1-X_{\mathrm{c}}}\right)^{0.4}
$$

where $\psi$ is the volume fraction of whiskers that participate in the load transfer, $X_{\mathrm{r}}$ is the volume fraction of the randomly 
Table 1. Mechanical Properties of Cellulose Whisker/Epoxy Nanocomposites Fabricated by Different Processes

\begin{tabular}{|c|c|c|c|c|c|}
\hline whisker & processing method & whisker content $(\% \mathrm{w} / \mathrm{w})$ & whisker content $(\% \mathrm{v} / \mathrm{v})$ & $E^{\prime}$ at $30^{\circ} \mathrm{C}(\mathrm{GPa})$ & $E^{\prime}$ at $185^{\circ} \mathrm{C}(\mathrm{MPa})$ \\
\hline & & 0 & 0 & 1.6 & 16 \\
\hline cotton & solvent exchange & 7.5 & 6 & 2.7 & 64 \\
\hline cotton & solvent exchange & 10 & 8 & 3.1 & 99 \\
\hline cotton & solvent exchange & 15 & 12 & 3.4 & 185 \\
\hline cotton & solvent exchange & 20 & 16 & 3.5 & 215 \\
\hline cotton & solvent exchange & 25 & 20 & 3.1 & 312 \\
\hline cotton & solvent exchange & 30 & 24 & 3.6 & 561 \\
\hline cotton & lyophilization & 10 & 8 & 1.9 & 78 \\
\hline cotton & lyophilization & 15 & 12 & 2.8 & 110 \\
\hline cotton & lyophilization & 25 & 20 & 2.7 & 165 \\
\hline tunicate & solvent exchange & 5 & 4 & 2.2 & 355 \\
\hline tunicate & solvent exchange & 7.5 & 6 & 3.4 & 670 \\
\hline tunicate & solvent exchange & 10 & 8 & 3.6 & 817 \\
\hline tunicate & solvent exchange & 15 & 12 & 3.7 & 1100 \\
\hline tunicate & solvent exchange & 20 & 16 & 4.9 & 1630 \\
\hline tunicate & solvent exchange & 25 & 20 & 5.7 & 2400 \\
\hline tunicate & solvent exchange & 30 & 24 & 4.7 & 1380 \\
\hline tunicate & lyophilization & 10 & 8 & 3.5 & 620 \\
\hline tunicate & lyophilization & 20 & 16 & 5.4 & 1660 \\
\hline
\end{tabular}

oriented filler, $X_{\mathrm{c}}$ is the critical whisker percolation volume fraction calculated by $0.7 / A$ where $A$ is the aspect ratio of the filler, and $E_{\mathrm{s}}^{\prime}$ and $E_{\mathrm{r}}^{\prime}$ are the tensile storage moduli of the neat polymer matrix and the reinforcing filler, respectively. Figure 7 shows that the experimentally determined $E^{\prime}$ values (shown are data at $185^{\circ} \mathrm{C}$ ) of all here-investigated tunicate can be well described by eq 1 , regardless of the processing method, i.e., dispersion via the solvent exchange route or redispersion of lyophilized whiskers. The value of $\psi$ was approximated by eq 2 from $X_{\mathrm{r}}$ and the $X_{\mathrm{c}}$. The aspect ratio $A$ of tunicate whiskers was experimentally determined from TEM images of individualized whisker to be $84 . E_{\mathrm{s}}^{\prime}$ was determined by DMTA to be 16 MPa for a neat epoxy film. $E_{\mathrm{r}}^{\prime}$ was also estimated by DMTA by testing solution-cast films of the neat tunicate whiskers; our previous studies revealed a stiffness range between 4 and $13 \mathrm{GPa}(21,33,34)$ for these samples. Surprisingly, unlike all of our previously explored tunicate whisker nanocomposites (23-26), the shear storage moduli of the new tunicate whisker/epoxy nanocomposites are much higher than the predictions made by this framework (Figure 7). Interestingly, the percolation model and the experimental data match very nicely if $E_{\mathrm{r}}^{\prime}$ is increased from 13 to $24 \mathrm{GPa}$. Dufresne et al. (16) suggested that strong interactions between the whiskers and the matrix polymer could result in the formation of whisker-bound matrix polymer layer around the whiskers, which would effectively increase the volume fraction of the rigid phase and result in an increase of $E^{\prime}$. Thus, in cases where strong matrix-whisker interactions are at play, the percolation model may underestimate $E^{\prime}$. Indeed, a review of our own data on several tunicate nanocomposites $(21-26)$ suggests a trend, in which $E_{\mathrm{r}}^{\prime}$, determined by a least-squares fit of eq 1 to the experimental data instead of DMTA analysis of a whisker film, increases with the polarity of the matrix polymer, suggesting that systems with pronounced whisker-matrix interactions, such as the one studied here, may exhibit larger than expected reinforcement. A detailed investigation of this aspect is currently in progress.

The $E^{\prime}$ values for the cotton whisker/epoxy nanocomposites made by the solvent exchange route also fit the percola- tion model well (Figure 8). Here experimental values for $A$ (10.5), $X_{\mathrm{C}}(0.07), X_{\mathrm{r}}(0-0.3)$, and $E_{\mathrm{S}}^{\prime}(16 \mathrm{MPa})$ were used and eq 1 was fitted to the data to elucidate $E_{\mathrm{r}}^{\prime}$. The determined $E_{\mathrm{r}}^{\prime}$ value of $4.0 \mathrm{GPa}$ is also higher than the range reported before $(0.2-0.7 \mathrm{GPa})(23,46)$, which qualitatively mirrors the situation of the tunicate whisker based nanocomposites discussed above. Figure 8 reveals further that the nanocomposites made from redispersed lyophilized cotton whiskers display a considerably lower stiffness than materials of similar composition made from cotton whiskers dispersed by solvent-exchange. This finding is consistent with some whisker aggregation in case of the former and underlines again the usefulness of the new method. To the best of our knowledge, this is the first report of significant mechanical reinforcement of a (nonwater-based) epoxy resin with cellulose whiskers isolated from cotton, which on account of its availability and cost, is an attractive source of cellulose nanofibers.

\section{CONCLUSIONS}

A simple solvent exchange process has allowed to efficiently transfer tunicate and cotton cellulose whiskers from aqueous into organic (DMF) dispersions. Mixing with an oligomeric diglycidyl ether and an multifunctional amine cross-linker, subsequent casting and curing, allowed the fabrication of thermosetting nanocomposites in which the nanofillers are well-dispersed. These materials display a significant mechanical reinforcement, especially above $T_{\mathrm{g}}$. The effect is well-described by the percolation model and is indicative for the formation of a percolating whisker network in which stress transfer is facilitated by hydrogen-bonding between the whiskers. The observed reinforcement effect is higher than expected, suggesting that (presumably strong hydrogen bond) interactions among the whiskers and the polar matrix may contribute to the stress transfer.

Acknowledgment. We thank Dr. Midori Hitomi, Dr. Amir Avishai, and Dr. Lorraine Hsu for the TEM and SEM charac- 
terization and Dr. Matt Gawryla for help with the lyophilization of cellulose whisker dispersions. We are also indebted to Dr. Jeffrey Capadona, James Mendez, Kadhiravan Shanmuganathan, and Dr. Stuart Rowan for valuable discussions.

Supporting Information Available: Photographs of tunicate whisker dispersions in DMF made by lyophilization and solvent exchange; TEM images of tunicate whiskers deposited from aqueous or organic dispersions; Photographs of nanocomposite films comprising $16 \% \mathrm{v} / \mathrm{v}$ cellulose whiskers prepared by lyophilization and solvent exchange routes; SEM images of the fractured surfaces of $8 \% \mathrm{v} / \mathrm{v}$ cellulose whiskerl epoxy nanocomposites made by lyophilization and solvent exchange; $E^{\prime}$ vs temperature plots of cellulose whisker/epoxy nanocomposites made by lyophilization (PDF). This material is available free of charge via the Internet at http://pubs. acs.org.

\section{REFERENCES AND NOTES}

(1) Hussain, F.; Hojjati, M.; Okamoto, M.; Gorga, R. E. J.J. Compos. Mater. 2006, 40, 1511

(2) Ajayan, P. M.; Schadler, L. S.; Braun, P. B. Nanocomposite Science and Technology; Wiley VCH: Weinheim, Germany, 2003.

(3) Azizi Samir, M. A.; Alloin, F.; Dufresne, A. Biomacromolecules 2005, 6, 612

(4) Eichhorn, S. J.; Dufresne, A.; Aranguren, M.; Capadona, J. R.; Rowan, S. J.; Weder, C.; Thielemans, W.; Roman, M.; Renneckar, S.; Gindl, W.; Weigel, S.; Yano, H.; Abe, K.; Nogi, M.; Mangalam, A.; Simonsen, J.; Benight, A. D.; Bismarck, A.; Berglund, L. A. J. Mater. Sci. 2010, 45, 1

(5) Rånby, B. G. Acta Chem. Scand. 1949, 3, 649-650.

(6) Rånby, B. G.; Ribi, E. Experientia 1950, 6, 12-14.

(7) Rånby, B. G. Disc. Faraday Soc. 1951, 11, 158.

(8) Svagan, A. J.; Samir, M. A. S. A.; Berglund, L. A. Adv. Mater. 2008, 20, 1263

(9) Orts, W. J.; Shey, J.; Imam, S. H.; Glenn, G. M.; Guttman, M. E.; Revol, J. J. Polym. Environ. 2005, 13, 301

(10) Sturcova, A.; Davies, J. R.; Eichhorn, S. J. Biomacromolecules 2005, 6, 1055 .

(11) Rusli, R.; Eichhorn, S. J. Appl. Phys. Lett. 2008, 93, 033111

(12) Favier, V.; Chanzy, H.; Cavaille, J. Y. Macromolecules 1995, 28, 6365

(13) Azizi Samir, M. A.; Alloin, F.; Sanchez, J. F.; Dufresne, A. Polymer 2004, 45, 4149 .

(14) Azizi Samir, M. A.; Alloin, F.; Sanchez, J. F.; Kissi, N.; Dufresne, A. Biomacrolecules 2004, 37, 1386.

(15) Chazeau, L.; Cavaillé, J. Y.; Canova, G.; Dendievel, R.; Boutherin, B. J. Appl. Polym. Sci. 1999, 71, 1797.

(16) Bubief, D.; Samain, E.; Dufresne, A. Macromolecules 1999, 32, 5765 .

(17) Anglès, M. N.; Dufresne, A. Macromolecules 2000, 33, 8344.
(18) Ljungberg, N.; Bonini, C.; Bortolussi, F.; Boisson, C.; Heux, L.; Cavaillé, J. Y. Biomacromolecules 2005, 6, 2732.

(19) Morin, A.; Dufresne, A. Macromolecules 2002, 35, 2190.

(20) Schroers, M.; Kokil, A.; Weder, C. J. Appl. Polym. Sci. 2004, 93, 2883.

(21) Capadona, J. R.; van den Berg, O.; Capadona, L. A.; Schroeter, M.; Rowan, S. J.; Tyler, D. J.; Weder, C. Nat. Nanotechnol. 2007, 2, 765 .

(22) Capadona, J. R.; Shanmuganathan, K.; Tyler, D. J.; Rowan, S. J.; Weder, C. Science 2008, 319, 1370

(23) Capadona, J. R.; Shanmuganathan, K.; Trittschuh, S.; Seidel, S.; Rowan, S. J.; Weder, C. Biomacromolecules 2009, 10, 712.

(24) Shanmuganathan, K.; Capadona, J. R.; Rowan, S. J.; Weder, C. Prog. Polym. Sci. 2010, 35, 212.

(25) Shanmuganathan, K.; Capadona, J. R.; Rowan, S. J.; Weder, C. J. Mater. Chem. 2010, 20, 180

(26) Shanmuganathan, K.; Capadona, J. R.; Rowan, S. J.; Weder, C. ACS Appl. Mater. Interfaces 2010, 2, 165.

(27) Cao, X.; Dong, H.; Li, C. M. Biomacromolecules 2007, 8, 899

(28) Wu, Q.; Henriksson, M.; Liu, X.; Berglund, L. A. Biomacromolecules 2007, 8, 3687

(29) Epoxy Resins: Chemistry and Technology, May, C. A., Ed. Dekker, New York, 1976, p485.

(30) Shimokawa, T.; Hamaguchi, Y. J. Compos. Mater. 1984, 17, 64.

(31) Reis, P. N. B.; Ferreira, J. A. M.; Antunes, F. V.; Richardson, M. O. W. J. Compos. Mater. 2009, 43, 2609.

(32) Lu, J.; Askeland, P.; Drzal, L. T. Polymer 2008, 49, 1285.

(33) Matos Ruiz, M.; Cavaillé, J. Y.; Dufresne, A.; Gérard, J. F.; Graillat, C. Compos. Interfaces 2000, 7, 117.

(34) Matos Ruiz, M.; Cavaillé, J. Y.; Dufresne, A.; Graillat, C.; Gérard, J. F. Macromol. Symp. 2001, 169, 211

(35) van den Berg, O.; Capadona, J. R.; Weder, C. Biomacromolecules 2007, 8, 1353

(36) van den Berg, O.; Schroeter, M.; Capadona, J. R.; Weder, C. J. Mater. Chem. 2007, 17, 2746.

(37) Azizi Samir, M.; Alloin, F.; Sanchez, J. Y.; Kissi, N.; Dufresne, A. Macromolecules 2004, 37, 1386

(38) Viet, D.; Beck-Candanedo, S.; Gray, D. G. Cellulose 2007, 14, 109.

(39) Dong, X. M.; Revol, J. F.; Gray, D. G. Cellulose 1998, 5, 19.

(40) Sun, C. J. Pharm. Sci. 2005, 94, 2132.

(41) Le Cam, E.; Frechon, D.; Barray, M.; Fourcade, A.; Delain, E. Proc. Natl. Acad. Sci. U.S.A. 1994, 91, 11816.

(42) These data are averaged from 50-70 individual whiskers in TEM images.

(43) Hasani, M.; Cranston, E. D.; Westman, G.; Gray, D. G. Soft Matter 2008, 4, 2238

(44) Takayanagi, M.; Uemura, S.; Minami, S. J. Polym. Sci., Part C: Polym. Lett. 1964, 5, 113.

(45) Ouali, N.; Cavaillé, J. Y.; Pérez, J. Plast. Rubber Compos. 1991, 16, 55.

(46) Yamanaka, S.; Watanabe, K.; Kitamura, N.; Iguhci, M.; Mitsuhashi, S.; Nishi, Y.; Uryu, M J. Mater. Sci. 1989, 24, 3141 